\section{References}

1 Quraishi S, Wade W, Black D. Development of a GMC aligned curriculum for internal medicine including a qualitative study of the acceptability of 'capabilities in practice' as a curriculum model. FHJ 2019;6:196-203.

2 Lewis S, Young B, Thurley P et al. Does cost feedback modify demand for common blood tests in secondary care? A prospective controlled intervention study. FHJ 2019;6:204-8.

3 Robinson R, Bhattarai M, Hudali T, Vogler C. Predictors of 30-day hospital readmission: The direct comparison of number of discharge medications to the HOSPITAL score and LACE index. FH] 2019;6:209-14.
4 Dormandy L, Mufti S, Higgins E, Bailey C, Dixon M. Shifting the focus: A QI project to improve the management of delirium in patients with hip fracture. FHJ 2019;6:215-9.

5 Kabir M. Does artificial intelligence (AI) constitute an opportunity or a threat to the future of medicine as we know it? $\mathrm{FH}]$ 2019:6:190-1.

6 Hendriks JML, Fabritz L. AI can now identify atrial fibrillation through sinus rhythm. Lancet 2019;394:812-3.

7 NHS. The NHS long term plan. NHS, 2019. www.longtermplan. nhs.uk/wp-content/uploads/2019/08/nhs-long-term-plan-version1.2.pdf

8 Royal College of Physicians. RCP annual conference: Medicine 2020. https://rcpmedicine.co.uk/2020

\title{
Learning to speak up and to learn differently
}

We are delighted to introduce an issue of $\mathrm{FH}$ in which we have focused our minds, and hopefully those of our readers, on the ever-present activity of all clinicians (and humans) - learning. This is such a wide topic, so we have considered a number of different dimensions with the confidence that these will stimulate interest, debate and discussion. Firstly, we have considered the important issue of learning to speak up in our workplaces. The need for us all to feel able to speak up within a culture of psychological safety is crucial and the national gurdian for the NHS, Dr Henrietta Hughes, describes what has happened since the introduction of freedom to speak up guardians to the NHS, and her intended future developments of the role. ${ }^{1}$ Barriers perceived by trainees in being able to raise concerns, and possible ways to overcome these are described by $\mathrm{Dr}$ Irene Gafson and colleagues. ${ }^{2}$ In addition, in response to the lack of gender balance on panels, conference programmes and committees, the Women Speakers in Healthcare initiative has provided a solution on how women may finally be given an equal voice at conferences and other external events. ${ }^{3}$ We thank the authors, along with Prof Dame Jane Dacre, who has contributed a commentary to the article, and hope that this will advance the work being done across the NHS on equality, diversity and inclusivity for all.

The future of healthcare is ever changing as the modern NHS team increasingly delivers care wrapped around the patient informed by ever growing datasets from multiple sources. We need to learn differently in response to 'big data', not least in understanding how we can assimilate and process the volume and veracity of new knowledge (doubling of new knowledge in 1950 was a 50 year cycle, projected to be doubling every 73 days by 2020). ${ }^{4}$ It is also essential to learn how we can get the best out of new technology, and ensure education and training remains responsive and relevant as we move through the 21 st century. Ways that we can learn from the gaming industry and use immersive technologies to transform delivery of traditional medical education is described by Dr Jack Pottle. ${ }^{5}$ An example of a relatively easy change to refresh any stale session or programme is described in a paper on 'flipped' learning - outlining benefits and some tips for troubleshooting. ${ }^{6}$ The senior leadership of the (soon-to-be regulated) Faculty of Physician Associates and co-contributers discuss learning in the modern team from the perspective of physician associates (PAs) and their shared experiences - a topic that has been covered in depth with a number of real-life practical examples in the Royal College of Physicians' (RCP's) report Never too busy to learn. ${ }^{7,8}$ In addition, our personal learning is strengthened from not always succeeding and may be even more significant in our development as described in 'Not winning is good for you'. 'We would also like to highlight a powerful piece discussing modern slavery, written by a doctor in training who responded to her patient's basic - but hidden - need and shared her knowledge in a very sustainable way, through education. ${ }^{10}$

The new changes to the internal medicine curriculum are explained in a paper outlining an evaluation of a different approach to the vital supervisory relationship at the core of all training programmes. ${ }^{11}$ We are sure there will be more data to come with our first internal medicine trainee from August 2019. Reflecting on the RCP's chief registrar programme and other opportunities to develop generic professional capability in leadership, project management and improvement science, Dr Helen Grote and co-authors describe their lived experience of these schemes and their benefit to the wider NHS. ${ }^{12}$

So while many of us perceive that educational theory can be incredibly complex, the fundamentals of sharing knowledge are not. We would like to draw your attention to Maslow's hierarchy of human needs of safety and security (despite what some modern infographics might have you believe, WiFi and electricity are not necessarily everyone's basic needs) that are readily applicable to learning in any team. A culture that lacks psychological safety creates a climate of fear and vulnerability such that the effort put into detailed curriculum mapping and high-quality teaching is lost. Every one of us is responsible for ensuring this does not happen. 
What we know matters but who we are matters more.

Brené Brown ${ }^{13}$

This has been an extremely rewarding edition to work on together, with huge thanks to the $\mathrm{FH}$ J editorial team who have succeeded in keeping us on track. A diverse range of contributors making us think more about how we can all make the most of all opportunities to speak up in a powerful way, and challenge ourselves to learn how to learn and to share what we have come to know in novel ways, in the rapidly evolving world of 21st century healthcare.

Emma Vaux

Senior censor and vice president (education and training), Royal College of Physicians

Jo Szram

Consultant respiratory physician, Royal Brompton \& Harefield NHS Foundation Trust

\section{References}

1 Hughes $\mathrm{H}$. Freedom to speak up - the role of freedom to speak up guardians and the National Guardian's Office in England. FHJ 2019:6:186-9.
2 Gafson I, Sharma K, Griffin A. Raising concerns in the current NHS climate: a qualitative study exploring junior doctors' attitudes to training and teaching. FHJ 2019;6:156-61.

3 Penfold R, Knight K, Al-Hadithy N, Magee L, McLachlan G. Women speakers in healthcare: speaking up for balanced gender representation. FHJ 2019:6:167-71.

4 Densen P. Challenges and opportunities facing medical education. Trans Am Clin Climatol Assoc 2011:122:48-58.

5 Pottle J. Virtual reality and the transformation of medical education. FHJ 2019;6:181-5.

6 Chowdhury TA, Khan H, Druce MR et al. 'Flipped learning': Turning medical education upside down. FHJ 2019;6:192-5.

7 Watkins J, Straughton K, King N. There is no 'I' in team but there may be a PA. FHJ 2019;6:177-80.

8 Royal College of Physicians. Never too busy to learn: How the modern team can learn together in the busy workplace. London: RCP, 2018.

9 Young T. Not winning is good for you. FHJ 2019;6:162-3.

10 Riley R. When slavery hides in the symptoms - are we ready to see it? FHJ 2019;6:164-6.

11 Quraishi S, Wade W, Black D. Development of a GMC aligned curriculum for internal medicine including a qualitative study of the acceptability of 'capabilities in practice' as a curriculum model. FHJ 2019;6:196-203.

12 Grote H, Smith J, Little J, Horridge M. Clinical leadership fellow schemes for junior doctors: a brief overview of available schemes and how to apply. FHJ 2019;6:172-6.

13 Brown B. Daring greatly. Avery, 2012.

\section{Ti: Royal College of Physicians}

\section{Advancing medical professionalism}

Articulating a modern professional identity helps doctors to understand and undertake the unique role they play in healthcare. Developed in consultation with healthcare professionals, patients and other stakeholders, this report from the Royal College of Physicians aims to help doctors improve their professionalism in practical ways.

It focuses on seven key aspects of professional practice:

$>$ doctor as healer

$>$ learner and teacher

$>$ patient partner

$>$ advocate

$>$ team worker

$>$ innovator

$>$ manager and leader

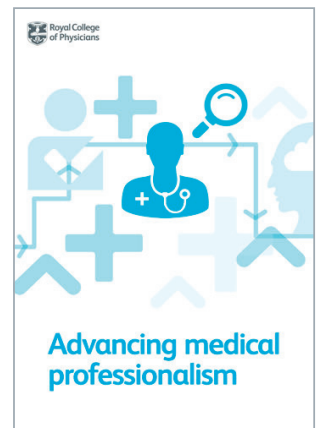

Download the report at: www.rcplondon.ac.uk/advancing-medical-professionalism 